ORIGINAL ARTICLE

\title{
Output power levels from mobile phones in different geographical areas; implications for exposure assessment
}

\author{
S Lönn, U Forssén, P Vecchia, A Ahlbom, M Feychting
}

Occup Environ Med 2004;61:769-772. doi: 10.1136/oem.2003.012567

See end of article for authors' affiliations

Correspondence to: Mr Stefan Lönn, Institute of Environmental Medicine, Karolinska Institutet, Box 210, S-171 77 Stockholm, Sweden; Stefan.Lonn@ imm.ki.se

Accepted 20 April 2004
Background: The power level used by the mobile phone is one of the most important factors determining the intensity of the radiofrequency exposure during a call. Mobile phone calls made in areas where base stations are densely situated (normally urban areas) should theoretically on average use lower output power levels than mobile phone calls made in areas with larger distances between base stations (rural areas).

Aims: To analyse the distribution of power levels from mobile phones in four geographical areas with different population densities.

Methods: The output power for all mobile phone calls managed by the GSM operator Telia Mobile was recorded during one week in four defined areas (rural, small urban, suburban, and city area) in Sweden. The recording included output power for the $900 \mathrm{MHz}$ and the $1800 \mathrm{MHz}$ frequency band.

Results: In the rural area, the highest power level was used about $50 \%$ of the time, while the lowest power was used only $3 \%$ of the time. The corresponding numbers for the city area were approximately $25 \%$ and $22 \%$. The output power distribution in all defined urban areas was similar.

Conclusion: In rural areas where base stations are sparse, the output power level used by mobile phones are on average considerably higher than in more densely populated areas. A quantitative assessment of individual exposure to radiofrequency fields is important for epidemiological studies of possible health effects for many reasons. Degree of urbanisation may be an important parameter to consider in the assessment of radiofrequency exposure from mobile phone use.
$\mathrm{T}$ he introduction and rapid increase of mobile telephony has been associated with public concern about possible health effects from this relatively new technology. The intensive research carried out in the past few years has been reviewed by several expert committees. ${ }^{1-6}$ The research effort is motivated by the rapid increase of mobile phone use; any possible health risk, even if small for individuals, would result in a relevant public health issue.

While the weight of evidence does not suggest adverse effects, the negative results cannot be considered conclusive. This is particularly true for epidemiological studies, which suffer from severe limitations in the exposure assessment and other methodological problems. The exposure parameters that may be significant for possible health effects have not been clearly identified. However, the exposure level is usually quantified in terms of specific absorption rate (SAR) of electromagnetic power in the user's head. The SAR depends on several factors, including the antenna type and position, the way the phone is handled, and, most importantly, the output power of the phone, which may change during the conversation.

The operator's network controls and adjusts the output power of each connected mobile phone to the lowest level compatible with a good signal quality. This is obtained by logarithmically scaling the power from the maximum ( 1 or $2 \mathrm{~W}$ at $1800 \mathrm{MHz}$ and $900 \mathrm{MHz}$, respectively) down to a level that may be as low as $1 \mathrm{~mW}$. Such adaptive power control (APC) takes place continuously, with the selected power level depending on several factors, including the distance from the base station, the presence of physical obstacles, whether the phone is used indoors or outdoors, and handovers.

Handover is the passage of control from one base station to another that takes place when the user moves across the borders of cells, or on request by the network control program to optimise the communication traffic. The frequency of handovers therefore depends on the user's movement, ${ }^{7}$ and the characteristics of the network that generally differ with geographical areas. Handovers are important for exposure assessment, because in connection to a handover, the output power of the phone is generally set to the highest level. ${ }^{8}$

Distance between the base station and the mobile phone user is a very important parameter that influences the output power used by the phone. One may hypothesise that mobile phone calls made in areas where base stations are densely situated (mostly densely populated urban areas) on average are using lower output power levels than mobile phone calls made in areas with larger distances between base stations (that is, rural areas). On the other hand, the effect might be compensated by a higher frequency of handovers in urban high traffic areas. Therefore, the geographic area may have implications for the exposure assessment in epidemiological studies as the SAR, that is, the exposure, is directly proportional to the output power used by the phone.

The purpose of this study is to analyse the distribution of power levels from mobile phones in four geographical areas with different population densities.

\section{METHODS}

Four geographical areas in Sweden with different population and base station densities were included (table 1). We defined as rural an area with low population density that consisted of small villages and countryside. A small town was selected to represent a small urban area. The Stockholm municipality was divided into two areas, defined as a suburban and a city area. Many people living in suburbs commute into the city for work, and therefore the actual size

Abbreviations: APC, adaptive power control; MRR, measurement result recording; SAR, specific absorption rate 


\section{Main messages}

- The power level used by the mobile phone, which can vary by more than a thousand-fold, is one of the most important factors determining the intensity of the radiofrequency exposure during a call.

- A quantitative assessment of individual exposure to radiofrequency fields is important for epidemiological studies of possible health effects for many reasons.

- Degree of urbanisation may be an important parameter to consider in the assessment of radiofrequency exposure from mobile phone use.

of the population staying in the different areas during the time mobile phone calls were made is unknown.

The GSM network controls the output power used by any connected mobile phone, and it is possible to record this information using dedicated software. The output power for all mobile phone calls managed by the operator Telia Mobile GSM in the defined geographic areas was recorded during one week in September 2001 (week 37). Telia used a software feature called measurement result recording (MRR) to measure and calculate the total distribution of output power levels from all connected mobile phones. The recording included output power for the $900 \mathrm{MHz}$ and the $1800 \mathrm{MHz}$ frequency band, except in the rural area where no $1800 \mathrm{MHz}$ network exists. The sampling period was $480 \mathrm{~ms}$. For each base station in the defined geographical areas, Telia delivered data on the total number of recorded signals per power level each day of the week, which allowed calculation of the sum of the total call time in each power level for all mobile phone calls transmitted through any of the base stations in the defined areas. The recorded signals were not divided by individual phone calls and therefore we could not determine number of calls, length of individual calls, or number of users. The recording of output power levels was divided into daytime (07 00-19 00) and night (19 00-07 00). Data were recorded in decibels $(\mathrm{dBm})$, with $\mathrm{dBm}=10 \times \log (\mathrm{P} /$ $\left.\left(1 \times 10^{-3}\right)\right)$, where $\mathrm{P}$ is the power in milliwatt $(\mathrm{mW})$. According to the communication protocols used by Telia, the $900 \mathrm{MHz}$ frequency band included odd values between 5 and $33 \mathrm{dBm}$, and the $1800 \mathrm{MHz}$ frequency band included even values between 0 and $30 \mathrm{dBm}$.

In the analysis, the median and the 25th and the 75th centiles were calculated for output power values in watts (W), for all areas and time periods in both the $900 \mathrm{MHz}$ and $1800 \mathrm{MHz}$ frequency bands. For both $900 \mathrm{MHz}$ and $1800 \mathrm{MHz}$ frequency bands, the proportion of call time at each power level was calculated separately for different areas and for weekdays and weekends (Friday $7 \mathrm{pm}$ to Monday $7 \mathrm{am})$.

Table 1 Basic information for included areas in the measurement of output power

\begin{tabular}{|c|c|c|c|c|}
\hline & Rural & Small urban & Suburban & City \\
\hline Area $\left(\mathrm{km}^{2}\right)$ & 7726 & 30 & 158 & 35 \\
\hline No. base stations & 112 & 90 & 189 & 958 \\
\hline $\begin{array}{l}\text { Population density } \\
\text { per } \mathrm{km}^{2}\end{array}$ & 6 & 1907 & 3175 & 7687 \\
\hline $\begin{array}{l}\text { Base station density } \\
\text { per } \mathrm{km}^{2}\end{array}$ & 0.01 & 3.00 & 1.20 & 27.37 \\
\hline
\end{tabular}

\section{RESULTS}

In total, the recorded data included approximately 250000 hours of transmission time. The rural area had approximately 25000 hours, the small urban area 17000 hours, and the suburban area 33000 hours. The city area had by far the longest call time with 175000 hours. The majority of the time was in the $900 \mathrm{MHz}$ band, covering approximately $65 \%$ of the total time; $80 \%$ of the call time was made during daytime, and $84 \%$ during weekdays.

Table 2 shows the median output power for all measured areas and time periods. The rural area had the highest median values and the small urban area had the lowest in the $900 \mathrm{MHz}$ frequency band. The median output power was lower during daytime on weekdays in the rural and suburban areas compared to the other time periods in the same area.

Figure 1 presents the relative distribution of output power levels for the $900 \mathrm{MHz}$ frequency band. The most frequently used power levels were the highest $(33 \mathrm{dBm})$ and the lowest $(5 \mathrm{dBm})$. All power levels between 5 and $33 \mathrm{dBm}$ had proportions less than $10 \%$. The output power distributions were similar for the different time periods, except in the suburban area where daytime calls on weekdays had a different distribution compared to the other periods. During daytime on weekdays, $28 \%$ of the call time was at $33 \mathrm{dBm}$ and $16 \%$ at $5 \mathrm{dBm}$ compared to almost $40 \%$ at $33 \mathrm{dBm}$ and $10 \%$ at $5 \mathrm{dBm}$ during the other time periods. In the rural area the highest power level was used about $50 \%$ of the time, while the lowest power was used only $3 \%$ of the time regardless of time period. The corresponding numbers for the city were approximately $25 \%$ and $22 \%$, respectively. The output power distribution in the suburban area and the small urban area were similar to that in the city. The results also showed that in the highest power level, the small urban area had the lowest proportion of the call time, even though the city area had more than twice as many base stations per $\mathrm{km}^{2}$.

Figure 2 shows the distribution of output power in the $1800 \mathrm{MHz}$ frequency band. As for the $900 \mathrm{MHz}$ frequency band, the highest proportions were for the lowest $(0 \mathrm{dBm})$ and the highest $(30 \mathrm{dBm})$ power levels. Furthermore, the comparison between different areas gives similar results, with the small urban area having the lowest proportion of call time at the highest available power level, and the city area the highest proportion at the lowest power level.

\section{DISCUSSION}

This study shows that mobile phones calls in the rural area operate at output power levels higher than in any other areas, which probably can be explained by the lower density of base stations. Such a conclusion is consistent with the data for the city area, where the density of base stations is much higher and the average output power is lower than in the rural area. The results also show that regulation of the output power is similar in the $900 \mathrm{MHz}$ band and the $1800 \mathrm{MHz}$ band. These findings indicate the importance of the distance from the user to the base stations for the exposure to radiofrequency fields from the mobile phone. However, our results indicate that the output power does not entirely depend on this factor, since the small urban area, where the density of base stations is lower than the city area, has the lowest proportion of call time at the highest power level. Such a finding could be explained by the number of recorded signals from mobile phones that are much lower in the small urban area than in the city area; the number of handovers requested to face traffic load is therefore likely to be fewer and perhaps there is also co-channel interference (frequency reuse leading to signal interference). Furthermore, buildings in a larger city are bigger than in a small town, which causes more signal attenuation and thereby a need for higher output power. 


\begin{tabular}{|c|c|c|c|c|}
\hline \multirow[b]{2}{*}{ Time } & \multicolumn{2}{|l|}{ Weekdays } & \multicolumn{2}{|l|}{ Weekend } \\
\hline & $0700-1900$ & $1900-0700$ & 07 00-1900 & $1900-0700$ \\
\hline \multicolumn{5}{|l|}{ 25th centile } \\
\hline Rural & $0.20 /-$ & $0.32 /-$ & $0.32 /-$ & $0.32 /-$ \\
\hline Small urban & $0.01 / 0.02$ & $0.01 / 0.02$ & $0.01 / 0.02$ & $0.01 / 0.01$ \\
\hline Suburban & $0.01 / 0.01$ & $0.05 / 0.03$ & $0.05 / 0.03$ & $0.05 / 0.03$ \\
\hline City & $0.01 / 0.01$ & $0.01 / 0.01$ & $0.01 / 0.01$ & $0.01 / 0.01$ \\
\hline \multicolumn{5}{|l|}{ Median } \\
\hline Rural & $1.26 /-$ & $2.00 /-$ & $2.00 /-$ & $2.00 /-$ \\
\hline Small urban & $0.05 / 0.10$ & $0.08 / 0.10$ & $0.08 / 0.10$ & $0.08 / 0.10$ \\
\hline Suburban & $0.13 / 0.10$ & $0.32 / 0.25$ & $0.50 / 0.25$ & $0.50 / 0.25$ \\
\hline City & $0.08 / 0.06$ & $0.20 / 0.10$ & $0.13 / 0.10$ & $0.20 / 0.10$ \\
\hline \multicolumn{5}{|l|}{ 75th centile } \\
\hline Rural & $2.00 /-$ & $2.00 /-$ & $2.00 /-$ & $2.00 /-$ \\
\hline Small urban & $0.50 / 0.63$ & $0.79 / 1.00$ & $0.79 / 1.00$ & $1.26 / 1.00$ \\
\hline Suburban & $2.00 / 1.00$ & $2.00 / 1.00$ & $2.00 / 1.00$ & $2.00 / 1.00$ \\
\hline City & $1.26 / 0.63$ & $2.00 / 1.00$ & $2.00 / 1.00$ & $2.00 / 1.00$ \\
\hline
\end{tabular}

The rural area has the highest output power during all measured time periods. The total output power seems to be lower during daytime on weekdays compared to other time periods, in both the rural and the suburban area. One possible explanation could be that there are more long calls during weekdays, especially during working hours, or that they more often are made outdoors. Unfortunately, our data do not contain information about call time for individual calls, so we cannot test this hypothesis. Theoretically, long calls have lower average output power than short calls, and it is reasonable to assume that calls during work are generally longer than private calls due to economic reasons.

The maximum power from GSM mobile phones in both the $900 \mathrm{MHz}$ and $1800 \mathrm{MHz}$ frequency bands is approximately
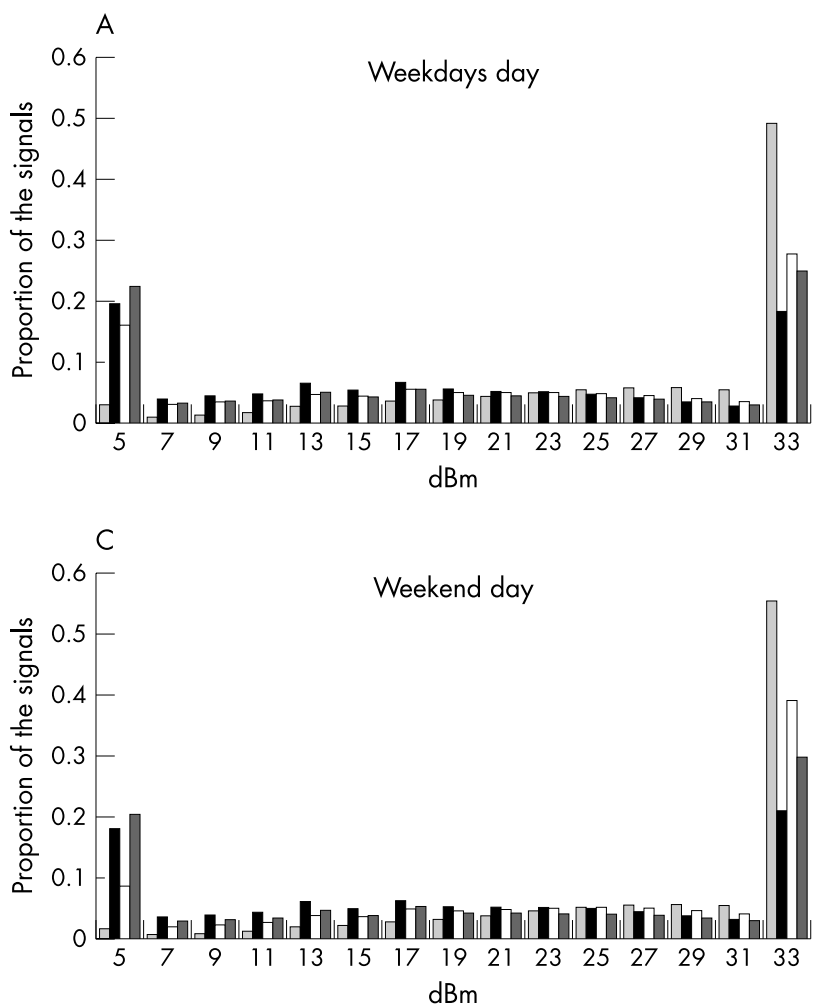

one thousand times higher than the lowest, and different distributions of power levels in various geographical areas may result in important differences in exposure levels between phone users. The network operator decides how the adjustment of the output power is performed, ${ }^{8}$ and the power levels can therefore differ between operators. Since the SAR level is directly proportional to the output power, the SAR will be influenced by decisions made by the operator. It is in the operator's interest that mobile phones use as low a power as possible due to technical reasons, ${ }^{8}$ such as problems with signal interference. However, operators may prioritise differently between a reliable transmission, and potential interference. Furthermore, APC has not always been used for all mobile phone systems. In the beginning (1981), the NMT
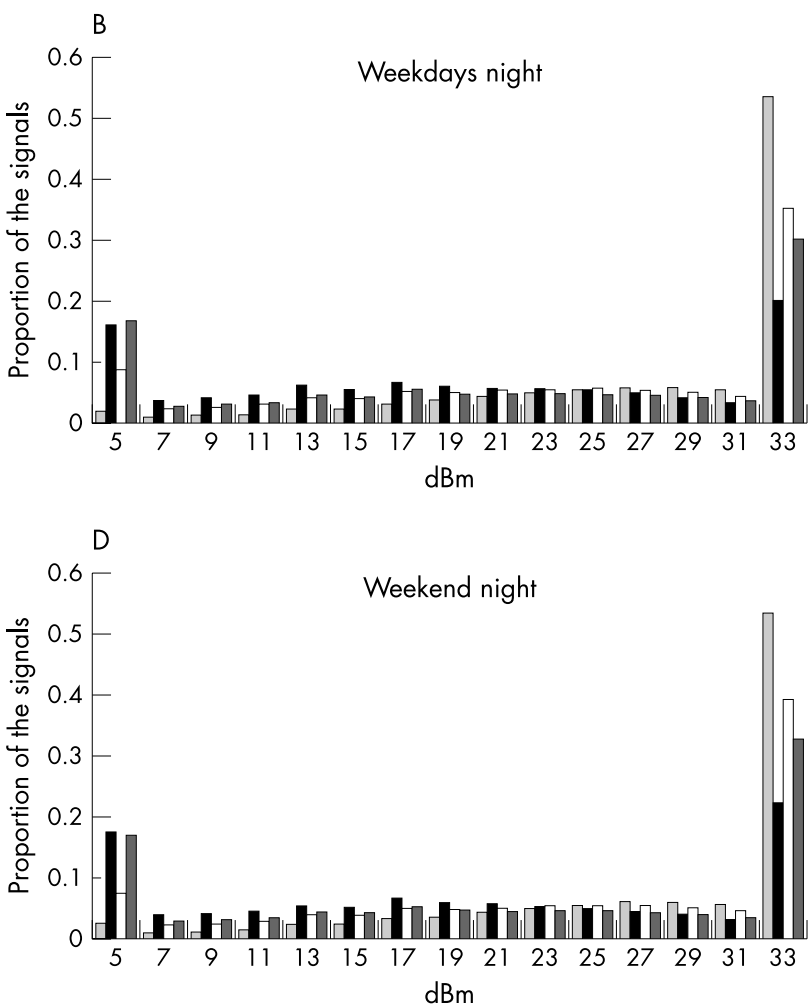

Figure 1 The distribution of output power levels from the $900 \mathrm{MHz}$ frequency band. The rural area is presented as light grey, small urban area as black, suburban area as white, and city area as dark grey. 

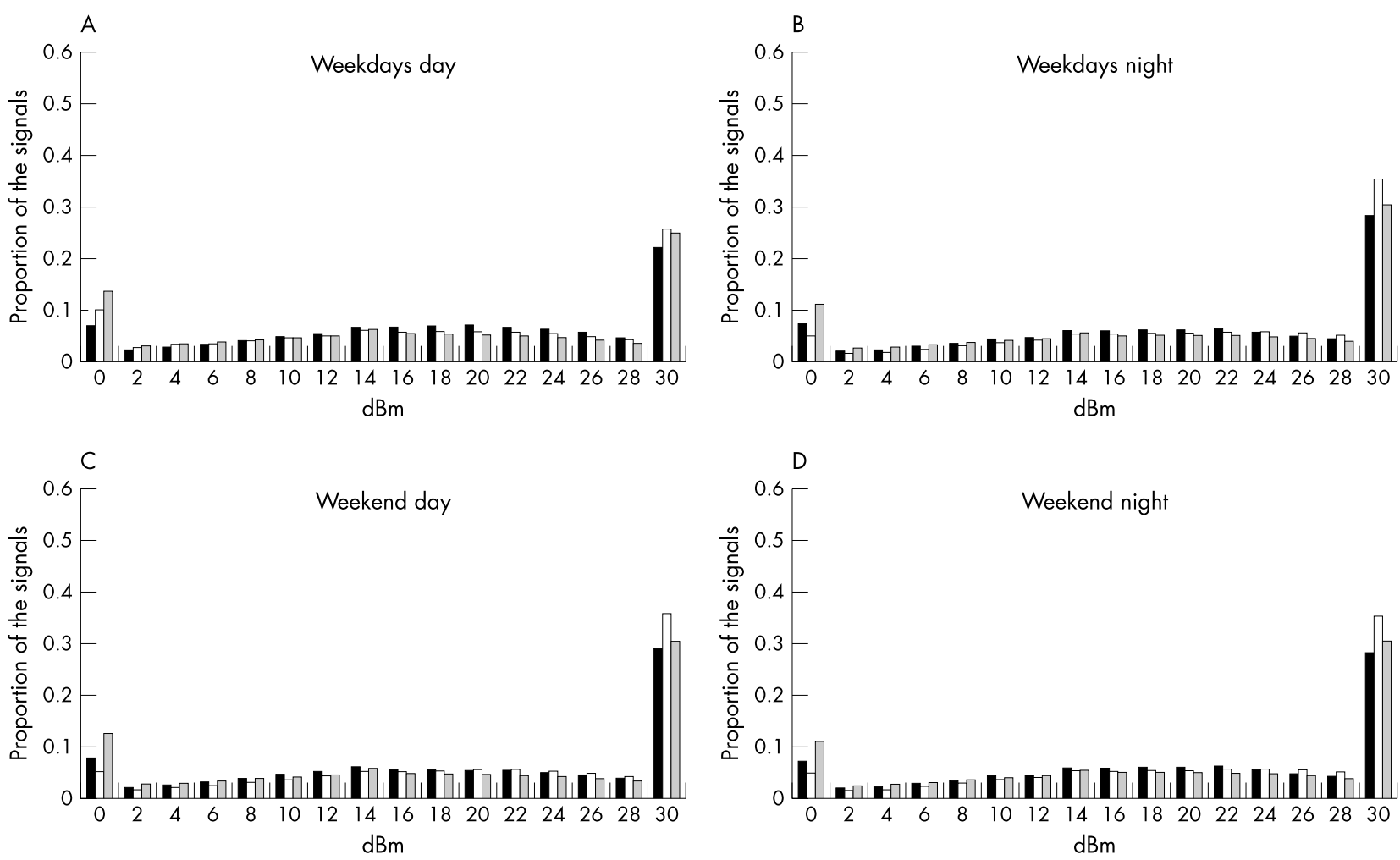

Figure 2 The distribution of output power levels from the $1800 \mathrm{MHz}$ frequency band. The small urban area is shown as black, the suburban area as white, and the city area as grey. The rural area did not have $1800 \mathrm{MHz}$ base stations.

system in the Nordic countries had no adjustment of the power, and therefore used the highest available power all the time. Later on, as a result of the increasing number of users, the NMT system was also regulated by APC. In addition, there are also output power differences between mobile phone models, ${ }^{9}$ even though these differences are much smaller than the differences between rural and urban areas.

All epidemiological studies performed so far have used a rather crude exposure assessment. At best, information about call time, laterality, and whether the phone is analogue or digital have been used, with no attempt to assess exposure intensity. A quantitative assessment of individual exposure to radiofrequency fields, rather than the simple use of mobile phones, is important for epidemiological studies of possible health effects related to mobile phone use. Several determinants of exposure have been theoretically identified and are presently investigated. The present study outlines the importance of the network, whose characteristics vary with type of geographical area. Information on where mobile phones are predominantly used may therefore help in building an effective exposure index. In particular, in rural areas where base stations are sparse, the output power level used by a mobile phone is on average considerably higher than in more densely populated areas.

While our results allow quite general conclusions on the relative importance of exposures in different areas, it should be noted that they refer to a GSM network and a single country, week, and operator. Performing similar surveys for other networks would provide a more comprehensive and clearer picture on this subject.

\section{ACKNOWLEDGEMENTS}

We acknowledge Telia Mobile AB for providing us with the output power data.

\section{Authors' affiliations}

S Lönn, U Forssén, A Ahlbom, M Feychting, Institute of Environmental Medicine, Karolinska Institutet, Stockholm, Sweden

P Vecchia, Physics Laboratory, National Institute of Health, Rome, Italy

\section{REFERENCES}

1 Royal Society of Canada. A review of the potential health risks of radiofrequency fields from wireless telecommunication devices. March, 1999. Available from: http://www.rsc.ca/english/RFreport.pdf (accessed 30 June 2003).

2 Independent Expert Group on Mobile Phones (IEGMP). Mobile phones and health. 11 May 2000. Available from: http://www.iegmp.org.uk/report/ index.htm (accessed 30 June 2003).

3 Health Council of the Netherlands. Mobile telephones. 28 January 2002. Available from: http://www.gr.nl/pdf.php?ID = 377 (accessed 30 June 2003).

4 Agence Française de Sécurité Sanitaire Environmentale (AFSSE). Téléphonie mobile et santé (in French). 21 March 2003. Available from: http:// www.afsse.fr/documents/AFSSE TM experts.pdf /accessed 30 June 2003).

5 NRPB. Health effects from radiofrequency electromagnetic fields: Report of an Independent Advisory Group on Non-ionising Radiation. 2003. DocNRBP 2;14:119-29. Available from: http://www.nrpb.org/publications/ documents_of_nrpb/pdfs/doc_14_2.pdf (accessed 30 March 2004).

6 SSI2003. Recent research on mobile telephony and cancer and other selected biological effects: First annual report from SSI's Independent Expert Group on Electromagnetic Fields. Swedish Radiation Protection Authority. 2003. Dnr 00/1854/02. Available from: http://www.ssi.se/english/ EMF_exp_Eng_2003.pdf (accessed 30 March 2004).

7 Wiart J, et al. Analysis of the influence of the power control and discontinuous transmission on RF exposure with GSM mobile phones. IEEE Transactions on EMC 2000;42(4).

8 ETSI GTS GSM 05.08 V5.1.0 (1996-07). Digital cellular telecommunications system (Phase 2+) (GSM); radio subsystem link control (GSM 05.08) Reference: DGTS/SMG-020508Q. Available from: http://webapp.etsi.org/ workprogram/Report_Workltem.asp?WKI_ID = 4727 (accessed 30 March 2004).

9 Anger G. SAR och utstrålad effekt för 21 mobiltelefoner. Statens Strålskyddsinstitut rapport 2002:01 (in Swedish). January, 2002. Available from: http://www.ssi.se/ssi_rapporter/pdf/ssi_rapp_2002_01.pdf (accessed 30 June 2003). 